\title{
Determinants of legitimization in Europe: an empirical analysis for 21 countries
}

\author{
HENRYK DOMAŃSKI \\ Institute of the Philosophy and Sociology, \\ Polish Academy of Sciences \\ hdomansk@ifispan.waw.pl
}

Recepción: noviembre 2004

Aceptación: mayo 2005

Social scientists have expressed a ceaseless flow of reflections about various challenges to legitimization of political systems. From Aristotle to the present down legitimization used to be equated with attitudes of approval of political and economic status quo. What is approved concerns government, political and economic systems, and rulers.

Most recently, theory of legitimization has analysed the ways in which modern liberal democracies were undermined by various tensions and strains. The main stream of these discussions culminated in theories of crisis of legitimization. One has to mention - although it concerns mainly historians- that crises of legitimacy are primarily a recent historical phenomenon. In Western civilisation they were attributed to collapses of old monarchies and feudal order. According to Lipset (1983), crises of legitimization became inherent in transition to modern social structures.

Phenomenon referred to crisis of legitimacy has been observed for many decades. Owing to historical circumstances of the recent decades, it became also an exacerbated question for Eastern European societies. Many writers offered subtle and complex theoretical explanations of its sources, however empirical findings are scarce, which especially concerns comparative data. This analysis attempts to make one step forward in that some hypotheses derived from previous theoretical prediction will be put to empirical verification. The purpose of this paper is to shed light on the general ,laws» as far as determinants of legitimacy are concerned. To this aim I will analyze data coming from European Social Survey carried out in 2002 . For the purposes of the present study, I pooled together ESS data from 21 countries. Our ,explained variable» is legitimization defined in terms of continuous measure that reflects extent to which individuals approve their political and economic system. In choosing ,explanatory variables» I drew from many theories of legitimacy crisis that emphasize both individual charac- 
teristics as well as macro-systemic contextual variables such as level of economic development or degree of corruption. The multilevel approach will be utilized to capture associations occurring on individual and contextual level in a quantitative way.

\section{DEFINITIONS OF CONCEPTS}

In the history of mankind there were no rulers - according to Weber (1968) - who would only rely on material and affective premises of their authority. Elites of power always sought to stimulate and cultivate popular belief in their legitimacy. Weber's definition of legitimacy is typical for his style of argumentation. He refers it to concept of «chances»: this is a chance that authority will be regarded as appropriate and treated so in practice» - although he added that it could be accepted by the ruled from purely opportunistic reasons. Out of the three weberian types of legitimization, that rational one (called legal) was referred to modern systems. As Weber put it, rational legitimacy was based on beliefs in legal character of laws and rights of wielding power by individuals appointed to their ruling positions by virtue of law (Weber 1968).

Contemporary theories revolve around crisis of legitimacy. One of the first explanations of this phenomenon was proposed by Lipset (1983). In Political Man he stated that crises of legitimization - that emerged during a transition to a new social structure- resided in the character of change in modern society. In a transitional period all the major groups do not have access to the political system, the status of major conservative institutions is threatened, and after a new social structure is established new system may be unable to sustain the expectations of major groups «for a long enough period of time» (1983: 65).

More recent theories of legitimacy crisis can be divided into three streams. The first focuses on the economic contradictions of the modern state. At the heart of these writings is the idea formulated by O'Connor (1973) that the state must meet two contradictory functions. First, it must create the favourable conditions to accumulation of capital in making various investments. Secondly, in laying grounds for its legitimacy the state must increase expenditures for welfare state provisions in areas of health, education, unemployment, etc. O'Connor argues that in attempts to meet these two functions, at the same time, the state faces a fundamental contradiction. On the one hand, government cannot reduce social welfare expenditure without a risk of serious political unrest and electoral defeat, while on the other hand, too much expenditures on social welfare undermine accumulation of resources and profits. Consequently, in seeking to meet these contradictory demands, the democratic state runs into increasing fiscal crisis.

The second version of theories of crisis of legitimacy concerns contradiction of political systems. The common feature of them is pointing out loss of trust in policy of state and increasing conflicts between interests of various subjects such 
as classes, regions, races, and sectors of economy. According to Offe (1996), the political unrests are provoked by erosion of loyalty to «welfare capitalism» among masses. Governments also must protect the interests of capitalists and maintain belief on stability in the private sector. In effect, the state is overloaded and cannot afford to pay. The legitimacy crisis emerges in form of new social movements, protest behaviors, demonstrations, marches, sits-in, and so, each of them expressing demands which came to rival traditional form of politics.

Jurgen Habermas (1987) gives slightly another version of political crisis of legitimacy. He called attention to a critical level of support and loyalty which must be maintained in order that law is obeyed and bureaucratic procedures are observed. Habermas, like Offe, perceptively noted that modern market societies must protect interests of capitalism, but at the same time must appear to be fair, impartial and just to all citizens. Consequently, democratic regimes existing under such strain not only face the difficulty of being illegitimate but also shift economic problems into political sphere which is inimical to rationality of making profits.

Third aspect of the legitimacy crisis has been located in area of values and norms. The first signs of the crisis were seen in the 1930s. Joseph Schumpeter (1952) identified it in the middle classes that -out of all «classes»- were most strongly aligned with the capitalist regime. He was struck by erosion of self-reliance, quest for self-improvement, self-discipline, and other orientations equated with the «protestant ethos». These argumentation gained wider support in later observations. Daniel Bell (1976) blamed capitalism for the erosion of individual responsibility and restraint. The loss of legitimacy - according to Bell- is rooted in two conflicting sets of values. On the one hand, these are values of the Puritan ethic - hard work, thriftiness, and sobriety - these are the values on which capitalism was built. On the other hand, there are values of hedonism: immediate gratification, personal pleasure, and expressiveness, which come into clash with the former and undermine the values that made capitalism a success.

Another point was raised by advocates of communitarianism such as Etzioni (1995). In contradiction to Schumpeter and Bell, he indicated on collapse of morality and civil virtues resulting from growing individualism, egoism, relativism, and utilitarianism. Still other aspects were emphasized by Robert Bellah and his associates in Habits of Heart. As they maintained: "Utility replaces duty, self-expression unseats authority. "Being good" becomes "feeling good" (Bellah et al. 1985). Their conclusion was that in today's millieu, the republican notion of doing good for one's country is practically incoherent and the public good has no meaning. Lastly, two left-wing critics, Christopher Lasch (1978) and Michael Harrington (1983) blame capitalism for deracination of our culture. Lasch contends that rugged capitalism has descended into a sea of narcissism. Individualism has become so extreme that nothing short of self absorption satisfies in this culture of decay. Harrington laments lack of transcend values and critisized capitalism for creating conditions which destroyed social bonds holding society together. 


\section{LEGITIMACY IN POST-COMMUNIST SOCIETIES}

Theories of legitimization crisis have been originally referred to Western democracies. They should not apply to Eastern European societies bearing in mind that with the fall of the communist system, long-lasting decades of the «deficit» of legitimization was ended. However paradoxical it may be, deficit of legitimization came back to the fore. This question emerged despite the fact that new democratic regimes won support from majority of people.

What does this loss of legitimization reflect? First, it can be explained in terms of disenchantment of elites. The striking feature of politics in post-communist societies is that political leaders have failed to elicit support from masses. Those originating from former anti-communist opposition were dismissed for their allgedly low professional experience in holding office. In turn, representatives of the former regime were blamed for reproduction of informal ties and being entrenched in old settings. Both are accused of indulgence, corruption, cynicism, and promoting particularistic interests to the detriment of interests of state (Offe 1999).

While denial of credibility of politicians is world-wide phenomenon, in the transition regimes it is paralleled by distrust to agencies of state. Perhaps it is not surprising. Institutionalization of political order was not given enough time to congeal into routinized patterns of legitimacy and standard operating procedures to which rulers, administrators and citizens would be bound. Anyway, public does not believe that decision-making bodies operate «for them». They are still perceived to close up «at the top» and «behind the scene» that prevents their internalization in people minds (Sztompka 1996). In public eyes they did not prove themselves in their normative functions. It undermines their role as trustmediating institutions - as Offe (1999) calls them - which mean that they are not capable of motivating, guiding and constraining law-makers, administrators, and the citizenry on the whole.

An important point about deficit of legitimization concerns failure of the newly created regimes to operate in a consistent way. Serious flaws reside in blurring accountability of local, and central governments, mutually contesting for taxation and coercive powers. The same applies to unclear separation between parliament, government, judiciary and other areas of power. According to theory of legitimization, agencies of state can win loyalty and compliance if their operation is anticipated - and inversely - their capacity for deriving legitimization is undermined if they fail to generate credible commitments of any functions that political and economic institutions are expected to perform. But post-communist regimes consist of patchwork of old and new rules without evident unifying principles. Changing property and taxation rights trigger regressive phenomena that inflict further damages, such as corruption, and increase impression of chaos (Elster et al. 1998). Such ,gaps» facilitate replacement of law for personalization of politics and evidence that institutions failed to inculcate their real meaning and mission to agents, and that the same rules are obeyed by everyone - from prime minister down to rank-and-file office holders. 


\section{HYPOTHESES ON DETERMINANTS OF LEGITIMACY}

The indicators of legitimacy may be stated in terms of popular beliefs in democracy, government, and economic performance of state. An unambiguous and convincing is definition of legitimacy as given by Lipset (1983:64) - that it involves the capacity of the system to engender and maintain the belief that the existing political institutions are the most appropriate ones for the society. It is reasonable to assume that despite common core root causes, legitimacy vary from country to country. In order to disclose its common foundations cross-national analyses are needed. Definition by Lipset will serve us as a starting point in formulation hypotheses regarding determinants of legitimacy.

The literature offers various types of explanation. In this section we will consider them in turn concentrating on their ability to explain legitimization's beliefs. Let us begin with distinction between «procedural» and «substantive» democracy. The purest form of the first is recognition by people formal rules which underpin working of social fabric, such as universal suffrage, predictability of decisions made by politicians, or political neutrality of agencies of state. In turn, the substantive democracy resides in acceptance of its «procedural» components stemming from satisfaction of demands and aspirations of people. While procedural democracy is precondition of legitimization, the substantive aspects of it lay at its core. Both of them will be put into empirical test in analyses presented below with more emphasis given to procedural democracy which has more empirical content and seem easier to measure.

Without running into a risk of simplification one can say that procedural democracy includes almost all components of the ideal type of bureaucracy by Weber - certainly, narrowed to agencies of state and filtered by perception and attitudes of people. We consider popular assessment of procedural democracy as a first source of legitimization which is to be taken into account. One can assume that it comprises various orientations such as belief that working of administration of state is actually based on impersonal and formally prescribed rules. Another one is that electorate exercise effective control over politicians, and the most overt - that government bodies are filled up according to competence, skills, and experience, which practically means that non-meritocratic criteria and nepotism should be erased.

These tenets find reflection in mechanisms underlying modern democracies. The available evidence suggests that beliefs in competence and authority of rulers are enhanced to the extent that groups and individuals see politicians as professional and reliable. To the degree that a significant proportion of population shares such views, people tend to cooperate with government and to observe basic responsibilities such as military service or systematic paying taxes. Another tangible requirement of effectiveness of democracy is meritocratic decisionmaking. All these signs of procedural democracy are relatively visible and its shortcomings display in corruption, and ineffectiveness of police and courts. Not surprisingly, these deficiencies took place more in post-commmunist societies 
due, in a large part, to their short experience with democratic institutions. As Offe (1999: 85) put it, both in Western and post-communist societies applies a rule saying that what creates good citizens are good government and law.

Guided by these theories we hypothesize that better evaluation of procedural democracy increases legitimization. For the sake of empirical analyses the complex notion of legitimacy will be reduced to composite measure of orientations -ranging from lack to maximum support for political and economic system. As regards procedural democracy it will be identified by opinions concerning how much politicians care about needs of common people and fulfill obligations. Our assumption is that positive opinions should reinforce legitimacy. Nevertheless, concern with «effect» of procedural democracy should be integrated into the broader framework - to accomplish it we will also use an objective yardstick of this factor, namely corruption. Our assumption is that higher corruption reflects worse performance of procedural democracy having, in turn, negative side-effect on legitimization.

Klingeman (1979) convincingly shown that political interest has an impact on the way people think about politics. This lead us to ask more general question on the role of political competence in affecting legitimacy with political competence equated with ability to understand and integrate facts into a general and coherent scheme. Higher political competence implies that a favorable attitude to state will be not easily threatened by conjectural failures and negative outcomes of opinion polls. Contrariwise, lower political competence is associated with stereotypes that can maintain disapproval of government and make individuals impervious to positive signs such as decline of unemployment, or successful performance of government in foreign affairs.

Political competence will be picked out by the level of formal schooling and syndrome of attitudes related to interest in politics and degree of its understanding by people. The point that formal education may capture political competence was effectively made by Lipset. In Political Man he hinted that multiple and politically inconsistent affiliations, loyalties and stimuli, reduce the emotion and aggressiveness involved in political choice. Chances for stable democracy are enhanced to the extent that group and individuals have a number of crosscutting, politically relevant affiliations with higher educated categories having more heterogeneous political environment (Lipset 1983: 77). Higher education plays also pivotal role in increasing intellectual flexibility, widening cognitive perspective and understanding politics.

More straightforward measures of political competence are peoples' views about their understanding of politics. Modern conception of democracy rests on the principle that norms, practices and claims to authority are open to discussion and may be discursively redeemed. This means that whatever important decisions are occurring, public spaces involving criticism and articulation of alternatives must be provided. Although unconstrained discourse generates restless tensions, it is not inimical to stability. To the contrary, being mediated and influenced by political competence, it tends to maintain beliefs in legitimization of 
government and state (Cohen 1999). Dwelling on this rationale we will examine to what extent comprehension of politics by common people can positively affect legitimacy.

One major contribution to crisis legitimacy theory was the emphasis on the dynamic and creative side of social trust. Robert Putnam (1993) in his influential book Making Democracy Work, convincingly argued that a civic culture of «generalized trust» and social solidarity between citizens, willing to cooperate, is an important societal prerequisite of working democracy. One can speculate since nobody tested this association in quantitative way - that willingness to cooperate and positive experience in mutual help, are transmitted to the level of relationship between citizens and state. Nonetheless rich illustration of this claim, provided by Putnam's community studies on civil culture, an important, critical point was taken up by Jean Cohen (1999). Insisting on two-sided character of this effect, she admits that democracy goes with personalized trust but the latter has to be reinforced by procedural fairness, impartiality, and justice coming from the side of state.

This suggests a need for more insightful study. «Capital of trust» will be traced in responses to questions concerning beliefs on whether confidence in relations with people makes sense. In sum, we expect that higher capital of trust produce higher support to political and economic system, and its lower resources make this support weaker. At the same -if Cohen's critique was correct-one may assume that these variables influence each other. In such case we should find a reciprocal causation between legitimacy and trust.

As economic theorists of legitimacy crisis implied, it results from fundamental contradiction between need for capital accumulation and expensive welfare provisions (Offe 1996). Governments face pressure of demands coming from various groups that run into fiscal crisis and political unrest. O'Connor's hypothesis was based on observations and there is no systematic evidence to support it as far as public attitudes are concerned. Having a comprehensive, comparative data set, we will examine to what extent legitimacy depends on claims to the welfare state. According to prevailing interpretations one can assume that support for welfare state goes hand in hand with decline of legitimization. The same should apply to potential effect of leftist orientations that are regarded -in theoretical reflection - to be inherently associated with support for redistribution of resources and embedded in sympathy to poor. Given these circumstances, leftist orientations seem to be a natural ally of all forces that undermine stability of existing order.

One cannot dismiss effect of voluntary associations. According to theories of mass society - whose coming was deemed first stage of the legitimacy crisis- modern societies are integrated by a wide diversity of groups and organizations. In Arthur Kornhauser's (1959) words, by creating cross-cutting cleavages a number of organizations help stabilize and moderate political conflict. Conversely, individuals who lack such roots, are poorly integrated into society and tend to be alienated which led them to support violence and ant-democratic 
political movements. What threatens democracy is that mass societies are made up of an amorphous mass of isolated and atomized individuals. Resulting from it destruction of traditional bonds increased feelings of insecurity and heightened powerlessness of masses. As the mass theory maintains, individuals would be exposed to nihilistic attitudes if they were not integrated into variety of organizations such as churches, leisure clubs or community associations. Building on these statements we will see to what extent membership in voluntary associations enhances legitimacy of political system.

A number of elements speak for still another link, namely that between legitimization and placement in social structure. Direct connection between the social position and support for stability has been observed in a number of countries. While the hard core of the supporters disproportionately comes from more literate, higher income groups, lower classes are predisposed for lower legitimization. Their subversive attitudes reside in the material deprivation and economic uncertainty which find an outlet in radicalism and protests.

Once it is abundantly clear that low-status groups are more apt to contest status quo, we must be careful in seeking for all sources of delegitimization in the lower strata. The available historical evidence indicates striking withdrawal or even apathy of lower classes as far as mobilization to action undermining existing order is concerned. They contribute to overall instability only when activated by crises, especially if it is accompanied by strong millennial appeals.

To be accurate there is nothing surprising in what is referred to fatalism of the lower classes. One part of the answer to this question concerns their adaptability to the relatively lower standard of life. One of the first studies on this issue was undertaken by Walter Runciman (1966) - as he showed a major part of lower classes did not realize how big gap separates them from the upper reaches. Theory of group reference extended these notions in saying that low deprivation of poor resides in a lack of direct relations between them and higher status groups. Grievances of the poor are not exacerbated because they do not see wealth of the other side. The stimulating research on the values systems of social classes went further in pointing to lower educational and occupational aspirations of the working class. In comparison to the middle classes, manual workers appear less ambitious in seeking for success and their ability to adopt appropriate measures to implement the attainment of ends by a purposeful means-end chain was limited (Hyman 1954). Tendency to adjust lower aspirations to the objectively lower positions have been apparently confirmed in many countries (Kelley and Evans 1992), leading to spectacular conclusion that social inequalities tend to reproduce themselves by virtue of the silent (and unaware) approval of majority of the bottom classes. It may well be that similar class pattern display in attitudes to state. One can hypothesize that paralleling legitimacy of social stratification by lower classes, they also tend to legitimate the existing political order. We assume that the same relationship should hold for effect of the family incomes.

It is well-known that living in poor conditions does not exclude satisfaction from life. Using the Freedom House index, Inglehart (1990) disclosed that higher 
levels of happiness positively correlate with living in democratic regimes. Basing on results of the Eurobarometer and World Values Survey, he maintained that in societies with higher level of subjective well-being citizens tend to feel that both their life is fundamentally good and political institutions are legitimated and right. We will trace this relationship in most recent data in order to establish to what extent satisfaction from one's life translates into positive attitudes to the political system on the whole.

Like many theories, the legitimacy crisis theory refers to phenomena defined both in terms of individual and systemic linkages. The basic determinants of legitimization in the latter case include level of economic development accompanied by consumption and standard of life. The empirical grounds for believing that sustained economic growth is conducive for democracy are quite straightforward. Building on analyses of Diamond (1992) Burkhart and Lewis-Beck (1994), and many others (see Lane and Ersson 2003 for a review) one may conclude that economic development leads to stable democracy insofar as it brings changes in political culture and social structure. The latter tends to be transformed by urbanization, mass education, occupational specialization and growing organizational networks that mobilize mass participation in politics (Lerner 1958; Deutsch 1961).

Other authors see effect of economic development as being mediated by cultural values (Linz and Valanzuela 1994). Higher GNP per capita works indirectly by stimulating «culture of trust» including various norm with one of them being norm of «loyal opposition». The latter means that if the opposition wins an election, the ruling elite will turn power to it, confident that it will not be imprisoned for doing so and the new elite themselves subsequently hold elections in which they can freely compete for power. Positive outputs from economic system can also generate mass support called «diffuse support» by Easton (1953) it can be equated with generalized perception that the political system is inherently good even in difficult times of recession.

Hypothesis of the «diffuse support» brings us to the role of the «middle class». Admittedly, the middle class does not exists as a single, coherent entity with clearly circumscribed boundaries but is composed of different sections and fragments that frequently exhibit contrasting practices and beliefs. Despite its heterogeneity, there is a consistent evidence that middle classes are strongly committed to thrift, self-discipline, industriousness and that they more rely on themselves in life pursuits in comparison to the working class. All this is taken to suggest that a large middle class tends to maintain both economic and political stability. On the part of economics, representatives of this class provide effective performance of occupational roles and secure a continuous demand for consumer goods. In politics, the existence of the middle class mitigates potential clashes between radical working class and reactionary sections of upper reaches and power elites. Dwelling on these findings we will seek for determinants of legitimacy in social structure. One can assume that legitimacy should be higher in societies marked by larger middle class. 


\section{DATA AND VARIABLES}

While fundamental, the determinants of legitimacy have rarely been studied. In part, this is because the requisite data have not been available -understanding mechanisms of legitimacy requires both individual and country-level data. This study utilizes data from the first edition of European Social Survey carried out in 2002 in 21 countries. In each country the surveys were based on probability samples of men and women (with $N$ varying between 1800 and 2500), representing adult population in age range above 18 .

Since ESS was designed to capture things of relevance in integrating Europe respondents were asked many questions concerned political attitudes. To assess legitimacy, this study employs additive index based on responses to three questions: (i) « On the whole how satisfied are you with the present state of the economy in [name of the country]?», (ii) « Now thinking about the [country] government, how satisfied are you with the way it is doing its job?», (iii) How satisfy are you from the way democracy works?». Each response was coded from 0 (extremely dissatisfied) to 10 (extremely satisfied). Following exploratory factor analysis to check consistency of these reports, a summated legitimacy index was created by adding the three items. It ranges from 0 to 30 .

Assessing determinants of legitimacy necessitates multivariate analyses with emphasis on the temporal sequence of explanatory variables. We refer to OLS beginning with the model that includes only sex, age, education, and class position. I adopted, whenever possible, generic categories whose meanings are widely shared to avoid artificial ambiguities in interpretation. Sex was a dummy variable (male=1). Age was defined in terms of series of four categories (18-30, $31-39,40-59,60$ and more) with the last category being omitted in a regression model. Formal education is operationalized in number of years of schooling (from 0 to 30 ). As regards class position a sevenfold EGP class schema is used (see Erikson and Goldthorpe 1992). The theoretical justification for the categories themselves derives from a Weberian conception of class, as defined by the market and work situations of particular occupations. Class locations were identified in terms of three variables: occupation coded in ISCO 1988, supervisory role, and ownership. The sevenfold class schema consists of: (i) higher professionals and managers referred to higher service class, (ii), lower professionals and managers referred to lower service class, (iii) routine non-manual employees (omitted category in a regression model), (iv) small employers and self-employed workers, (v) skilled manual workers, (vi) non-skilled manual workers, (vii) farmers and agricultural laborers. For recent years EGP is the most widely used indicator in international research and believed a valid measure of class position in contemporary market systems.

In the second OLS model family income per capita will be added. In order to secure comparability, family incomes, which were originally coded in a country-specific currencies, were converted into log of incomes. Then we come to the third model, including subjective variables. Self-assessment of 
one's material position is identified by answers to the question: «Which of the descriptions on this card comes closest to how you feel about your household's income nowadays?» - there were for categories, from «living comfortably on present income» to "very difficult on present income». A dummy variable «satisfaction with incomes» was coded 1 if respondents chose description «living comfortably on present income». Next, a 10-points scale -referred in this analysis to «finding job»- was included to capture self-assessed market position; respondents were asked in this case: «Now using this card, how difficult would or easy would it be for you to get a similar or better job with another employer, if you wanted to»? The ESS also asked: «All things considered, how satisfied are you with your life as a whole nowadays? Please answer using this card, where 0 means extremely dissatisfied and 10 means extremely satisfied». Following Inglehart's (1999) analyses that showed non-trivial linkages between support for democracy and subjective well-being, it would be worthwhile to check whether satisfaction from life affects legitimization controlling for other factors.

Most of the prior reflection on legitimacy indicates that it resides, in part, in wisdom and fairness of elites. Benevolent elites must operate within the framework of constitutional legal guarantees. The anticipated effect of «reliability of politicians» will be identified by information from two questions: (i) «Using this card do you think that politicians, in general, care what people like you think?» (five-point scale from «hardly care» to «most politicians care»), (ii) «Would you say that politicians are just interested in getting people's votes rather in peoples' opinions?» where responses were coded from 1 («nearly all just interested in votes») to 5 («nearly all interested in opinions»). Through adding them the summated index of «reliability of politicians» was constructed.

As it was noted earlier, a legitimacy-building activity on a part of suppliers depends on their interest in politics and degree of understanding it. To measure effect of this factor, we took responses to two questions: (i) «How interested would you say are you in politics? Would you say that you are very interested, ..., not at all» and (ii) «How often does politics seem so complicated that you can't really understand what is going on? Please use this card». A summary index - referred to hereafter as «political competence»- was created by adding values of these two constituent variables.

Guiding premise of our analysis is that interpersonal trust is generalized to politics increasing legitimacy of existing order. Three particular questions asked respondents about interpersonal trust, namely: (i) «Using this card, generally speaking, would you say that most people can be trusted, or that you can't be too careful in dealing with people? Please tell me on a score of 0 to 10 , where 0 means you can't be too careful and 10 means that most people can be trusted?», (ii) «Do you think that most people would try to take advantage of you if they got the chance, or would they try to be fair?», (iii) "Would you say that most of the time people try to be helpful or that they are mostly looking out for themselves?». Responses — coded on scales from 0 to 
10 - appeared coherent which allowed to create index of trust with values ranging from 0 do 30 .

Claims to welfare state will be picked up by three questions: (i) «The less government intervenes in economy the better for country», (ii) "Government should reduce differences in incomes», (iii) «Employees need strong trade unions to protect their pay and working conditions». The summary measure called «anti-welfare» was created from summing items from these three fivepoint scales («strongly agree»-»strongly disagree»). Concomitant with claims for more state expenditures - which in theories of legitimacy have been regarded as signs of fiscal crisis of state - are leftist orientations. In order to capture them we dwell on self-assessments of political orientations retrieved from 10-point scale. The relevant question was: «In politics people sometimes talk of «left» and «right». Using this card, where would you place yourself on this scale, where 0 means the left and 10 means the right?».

Participation in voluntary organizations was identified on a basis of series of questions concerning membership in various organizations. A dummy variable was created, coded 1 if respondent reported membership in at least one of them.

Finally, in order to identify systemic determinants of legitimacy we need country-level variables. GNP per capita and rate of unemployment (both recorded in 2000) will be taken to capture effect of economic well-being, $\mathrm{Co}$ rruption Perception Index will be employed to identify effective working of democracy, and in order to measure impact of the middle class we will take relative share (in percentages) of higher professionals and managers, referred to service class under the EGP schema.

\section{DIFFERENCES BETWEEN COUNTRIES}

Let us begin with an overall picture of inter-country variation. In the first column of Table 1 mean levels of legitimacy index for 21 countries are presented. Looking through this data one can draw two preliminary conclusions. First, across European countries, mean level of legitimacy stands at 14.4 which suggests that support for governments was not too high but also not too low -it was about on average level on the scale ranging from 0 to 30 .

Second, there are substantial inter-country variations. The highest legitimacy turns out in the Scandinavian countries, and in Luxembourg and Switzerland, thus - in the latter cases - in small, and stable democracies. On the top is Denmark, with average legitimacy of 20.1, followed by Luxembourg (19.9), Finland (18.3), Switzerland (17.0), Norway and Sweden (16.5). On the opposite pole there are a group of countries including Poland, Portugal, Israel and Germany. One can easily see that societies marked by relatively low level of legitimacy have little in common and one can hardly find some explanation of their position referring to such factors as level of economic development, political system or the same culture. 
Table 1

Mean orientations in 21 countries. European Social Survey 2002

\begin{tabular}{|l|c|c|c|c|c|}
\hline \multicolumn{1}{|c|}{ Country } & Legitimacy & Trust & $\begin{array}{c}\text { Satisfaction } \\
\text { with life }\end{array}$ & $\begin{array}{c}\text { Reliability } \\
\text { politicians }\end{array}$ & $\begin{array}{c}\text { Satisfaction } \\
\text { of with } \\
\text { incomes }\end{array}$ \\
\hline Austria & 14.7 & 15.7 & 7.55 & 4.14 & 29.7 \\
Belgium & 16.1 & 14.9 & 7.44 & 4.73 & 39.8 \\
Czech Republic & 12.4 & 13.4 & 6.27 & 4.09 & 9.6 \\
Denmark & 20.1 & 20.4 & 8.44 & 5.88 & 63.0 \\
Finland & 18.3 & 19.0 & 7.91 & 5.28 & 21.2 \\
Germany & 11.0 & 15.2 & 6.81 & 4.29 & 27.9 \\
Greece & 13.3 & 10.3 & 6.26 & 3.50 & 10.6 \\
Hungary & 13.8 & 12.9 & 5.61 & 4.51 & 6.5 \\
Ireland & 13.7 & 17.4 & 7.46 & 4.63 & 37.1 \\
Israel & 10.9 & 14.4 & 6.42 & 4.06 & 16.8 \\
Italy & 13.0 & 13.2 & 6.86 & 4.16 & 33.8 \\
Luxembourg & 19.9 & 15.3 & 7.80 & 4.87 & 53.6 \\
Netherlands & 15.4 & 17.1 & 7.62 & 5.22 & 51.7 \\
Norway & 16.5 & 19.6 & 7.76 & 5.88 & 52.9 \\
Poland & 9.6 & 11.5 & 5.84 & 3.90 & 4.9 \\
Portugal & 10.9 & 12.9 & 5.76 & 3.54 & 8.9 \\
Slovenia & 12.8 & 12.9 & 6.57 & 3.96 & 37.9 \\
Spain & 14.7 & 14.5 & 6.93 & 3.93 & 28.1 \\
Sweden & 16.5 & 18.8 & 7.80 & 5.76 & 53.3 \\
Switzerland & 17.0 & 17.2 & 7.96 & 5.26 & 50.4 \\
United Kingdom & 14.6 & 16.0 & 7.02 & 4.76 & 39.9 \\
Mean & 14.4 & 15.4 & 7.06 & 4.59 & 32.0 \\
\hline
\end{tabular}

Although the Scandinavian countries, which represent the purest form of the welfare state system, appear to be most effective in seeking for support from the masses, it does not mean that the crux of the matter lies in the public spending and social expenditures themselves. There are also post-communist societies, such as Hungary and Poland, which secure expensive state provisions for health, pensions, and so, but authority of government in these countries is impaired and their ability to resolve political problems reduced. This relationship - between legitimacy and policy of generous provisions - is not straightforward in that governments can win support only in case if they are able to secure really big social provisions and do this in coherent and systematic way.

As far as countries with the lowest degree of legitimacy are concerned, at the bottom was Poland. One cannot attribute its lowest position to immature democracy, low civic culture or relatively low - on average - standard of life that could generate dissatisfaction from the way the government is doing. Situation in 
Poland does not depart in significant way from other post-communist societies - may be except of the GNP per capita - which, as compared to Czech Republic, Hungary and Slovenia, is really the lowest. Some rapid, and conjectural decline of support for political elites, is also hardly in stake, as ESS was carried out in 2002 - long before the leftist government by Leszek Miller lost confidence that finally led to its collapse in May 2004. It must be some durable phenomenon underpinning dramatically low legitimacy in Poland - in order to understand it let us look at other variables.

Examination of data in Table 1 suggests that distribution of legitimacy between nations is paralleled by inter-country variation in trust. Also in this case Poland appears to be located at the bottom, preceding only Greece. As regards general shape of this ranking, level of interpersonal trust has been consistently the lowest in post-communist societies —outstanding in widespread beliefs that «in dealing with people you can't be too careful», or «most of them would try to take advantage of you if they got the chance». We have also three Mediteranian societies - Portugal, Spain, and Greece - marked with relatively lower level of trust. On the one hand, it coincides with strong orientation on family and neigborhood ties, found in many analyses on this region, but on the other hand with widespread «amoral familialism» and deeply ingrained tradition of authoritarian rules (Medrano 1996). At the same time the highest level of trust occurs in Scandinavian countries, in general, with first four positions being occupied by Denmark, Norway, Finland, and Sweden. They clearly overrun Switzerland, Ireland, Netherlands and other Western societies.

As these figures show, beliefs that people can be trusted cluster neatly in democratic, welfare state regimes. Other evidence, presented in World Values Survey, from 1990, confirms this conclusion. According to the WVS data the highest level of interpersonal trust was discovered in Norway followed by Denmark and Sweden. Across almost 60 countries post-communist societies ranked in the middle, and the low level of trust displayed in Philippines, Puerto Rico, Brazil and Peru (Inglehart 1999: 91). Whatever factors stay behind this pattern they must be enduring. In Inghehart's view there were strong linkages between variations in interpersonal trust and economic development and religious tradition. Certainly, the richer societies were more trusting than people of poorer societies, but it was also Protestant and Confucian-influenced societies that showed consistently higher levels of interpersonal trust than did Roman Catholic and Islamic societies. Lower rank of Catholic societies Inglehart explained in terms of hierarchical and centrally controlled organization of Catholic church which tend to undermine close and direct relationships -contrariwise to Protestant churches which were smaller, relatively decentralized and more open to local control.

Fourth column of Table 1 informs about reliability of politicians in the public eyes. One can see that inter-country variations of reliability go hand in hand with legitimacy. Although countries' averages mask differences within nations there is no question that electorates of the three Scandinavian countries -Denmark, Norway, and Sweden - express the most favorable opinions about their elites. In 
vincinity of them were Finland, Switzerland and Netherlands. The lowest positions, though, on the reliability scale occupied politicians from Mediterranean societies on the whole, that is from Greece, Portugal, and Spain. Slightly above them were politicians from Poland. Czech Republic and Slovenia place themselves not so far from Poland which may be attributed to what Offe (1999) regards as resulting from immature democracy in post-communist nations. Notably, politicians were better assessed in Hungary -in mass opinion they were more reliable than politicians in Germany and Austria.

Reputaton of politicians coincided - to some extent - with hierarchy of satisfaction with one's life that reflects various constituent staisfactions - from material to purely spiritual ones. The satisfaction with life is mostly widespread in Denmark (8.4). It was visibly lower -with an average of 7.7-7.9 on ten points scale - in the next cluster of countries that included Finland, Switzerland, Sweden, Norway and Luxembourg. Relatively lowest level of overall satisfaction revealed Hungarians (5.6), Portuguese $(5,8)$ and Poles $(5.8)$. The notoriously low level of satisfaction in Hungary has been disclosed many times in international research on psychic health. There are many indications of the high level of depression in Hungarian society which was specifically reflected in relatively high rates of suicides.

It is noteworthy to say that Eurobarometer surveys, carried out since 1973 to the present, reveal a similar pattern. In every year the Scandinavian countries (especially the Dutch and the Danes) always rank near the top of satisfaction scale, while the Italians, French, Portuguese always rank near the bottom. The correlation between a given country's level of life satisfaction at the first time point for which data are available and its level in 1995 (the last time point) is .81 that can bespeak of high level of stability in time (Inglehart 1999: 113).

The last column of Table 1 reports data focussed more on material aspects of satisfaction, which is reflected in distribution of percentages of people who admitted to «live comfortably on present income». Not surpringly, as inspection of these figures suggests, satisfaction with family incomes correlates with intercountry variation in the general standard of life. According to our data the satisfaction with incomes was the highest in richest societs such as Denmark, Luxembourg, Switzerland, Netherlands, and Sweden. More than $50 \%$ of samples, coming from these societies, declared to enjoy comfortable level of life. There is especially close match between the highest feeling of the «comfort» among Danes (63\%) and the highest level of GNP per capita in this country. In 2000 it amounted to 33 thousands Euro (according to Eurostat data), whereas in Sweden and Ireland, which were two next countries, the GNP per capita stood at 27.3-27.8 thousands.

Satisfaction from family incomes gradually sank down with decline of the general standard of life. It was at worst in Poland where only $4.9 \%$ of the sample asked about incomes reported to have a feeling of comfort. Out of post-communist societies there were also Hungary and Czech Republic marked with low level of comfort from incomes (below 10\%). To this extent, thesis that the level 
of economic development can have a substantial effect on satisfaction with incomes is borne out, however cautionary note for this interpretation is needed. Aside from the GNP, some other factors must underlie feeling of comfort with incomes once we have also Portugal and Greece, located in neighborhood of post-communist societies, and the Slovenian case with $37.9 \%$ of respondents reporting to live comfortable on their family incomes. Slovenians placed themselves on the level of British and Belgians. At the same time, this category was relatively small in Austria, Finland, Germany, Italy, and Spain which suggests that effect of economics is not simple and direct.

\section{INDIVIDUAL-LEVEL DETERMINANTS OF LEGITIMACY}

To explain process of legitimacy we dwell on a pooled samples for 21 countries. We pursue two strategies. First, OLS estimation will be employed to determine effects of individual characteristics on legitimacy. In the second step we will incorporate macro characteristics of individual societies, such as GNP per capita or level corruption, to establish sources of cross-national variation.

Table 2 presents regression coefficients for independent variables. Model 1 refers to the gross effect of education and social class on legitimacy. It is to mention that in a preliminary step sex and categories of age were taken into account but we excluded them after checking that in the pooled data set they do not affect legitimacy in a significant way. Two findings are evident.

First, support for government depends in a significant way on formal education and class position although percent of variance explained by them $(1 \%)$ is modest. Second, they shape legitimacy according to a well-known pattern with more legitimacy received from highly educated categories and professionals and managers - at the same time legitimacy declines with membership in respectively «lower classes». One year of schooling increases legitimacy by .09 that may be considered as substantial net gain on the scale ranging from 0 to 30 . Turning to class category one may conclude that governments can rely, mostly, on members of service class, consisting of people better-off, who prefer stabilization and are less likely to rebel. The values of metric coefficients for six classes report how much legitimacy they offered, or withdrew, (positive and negative values respectively) relative to the mean level of legitimacy across 21 countries in creating dummies for classes I referred to the effect-coding and it is for this reason that values of parameters are referred to the grand means (see Cohen and Cohen 1983). It shows that legitimacy of professionals and managers stood at .77 higher relative to its mean level controlling for years of schooling. Conversely, owners and skilled workers were distinguished with the lowest support (.41-.42 point below the mean).

There is nothing striking in low level of legitimacy among small owners. Several writers have noted that for many, self-employment was an alternative to unemployment or the threat of unemployment. What we call the petite bourge- 
Table 2

Parameter estimates for determinants of legitimacy for pooled cross-country data in 2002

\begin{tabular}{|c|c|c|c|c|c|c|}
\hline \multirow{2}{*}{ Independent variables } & \multicolumn{2}{|c|}{$I$} & \multicolumn{2}{|c|}{ II } & \multicolumn{2}{|c|}{ III } \\
\hline & $b$ & beta & $b$ & beta & $b$ & beta \\
\hline Years of schooling & $.09 * *$ & .06 & $.03^{* *}$ & .02 & -.02 & -.01 \\
\hline $\begin{array}{l}\text { Occupational category: } \\
\text { Professionals and }\end{array}$ & & & & & & \\
\hline $\begin{array}{l}\text { managers } \\
\text { Lower professionals }\end{array}$ & $.77 * *$ & .06 & .24 & .02 & -.07 & -.01 \\
\hline and managers & .31 & .03 & .02 & .00 & -.30 & -.03 \\
\hline Owners & $-.42 * *$ & -.03 & -.41 & -.03 & .23 & .01 \\
\hline Skilled workers & $-.41 * *$ & -.03 & -.25 & -.02 & .25 & .02 \\
\hline Unskilled workers & -.33 & -.03 & -.21 & -.02 & .13 & .01 \\
\hline $\begin{array}{l}\text { Farmers and agricul- } \\
\text { tural labourers }\end{array}$ & .05 & .00 & $.64^{* *}$ & .04 & -.27 & -.01 \\
\hline Log of family incomes & - & - & $2.83^{* *}$ & .23 & $.41 * *$ & .03 \\
\hline Reliability of politicians & - & - & - & - & $.89 * *$ & .29 \\
\hline Trust & - & - & - & - & $.18^{* *}$ & .18 \\
\hline Satisfaction with life & - & - & - & - & $.67^{* *}$ & .23 \\
\hline Left-Righ & - & - & - & - & $.18^{* *}$ & .07 \\
\hline Anti-welfare & - & - & - & - & $.21^{* *}$ & .07 \\
\hline Satisfaction with & & & & & & \\
\hline incomes & - & - & - & - & $.60^{* *}$ & .05 \\
\hline Finding job & - & - & - & - & $.08^{* *}$ & .04 \\
\hline Interest in politics & - & - & - & - & .03 & .01 \\
\hline Intercept & 13.26 & - & 9.9 & - & -1.06 & - \\
\hline & .01 & - & .06 & - & .33 & \\
\hline
\end{tabular}

$* p<.05$. ** $p<.01$.

oisie displays great diversity containing within it old, even archaic forms of economic activity, such as craft or artisanal production. Recessions, sudden technological advances, the incursion of multi-national corporations with capital intensive enterprises, take-overs, and government sponsored «rationalisations» -all these destroy some opportunities and many representatives of small business live under threat of change. In periodic mobilizations they express oposition to organised labour, distaste for big business and its capacity to squeeze subsidies and concessions from governments (Curran and Blackburn 1991).

Model 2 extends analysis to family incomes per capita. Metric coefficient for family incomes is 2.83 , which is high in a substantive sense and statistically significant. Analysis presented in the second column prompts the following obser- 
vations. First, in determination of legitimacy family incomes matter much more than years of schooling and class membership taken in overall. When one adds family incomes to the first equation, one gains statistically significant increment in $\mathrm{R}^{2}$ (from 1 to $6 \%$ ) in comparison to the magnitude of $\mathrm{R}^{2}$ for model $\mathrm{I}$, including only education and class. Second, this variable effectively reduce the overall impact of education and social class suggesting that family incomes mediate in effect of educational credentials and class position. Clearly, after adding incomes the highest payoff to legitimacy comes from farmers, and net effect of membership in service class disappear. It means that advantages to legitimacy of being manager or profession result from relatively higher incomes of the latter. Some other factors must affect legitimacy in case of farmers.

Despite significant role of various attributes of socioeconomic status, legitimacy is directly affected by perceptions and evaluations of people. Model 3, which compares net effects of objective and subjective sources of legitimacy, shows that net effect of education and class vanished, and family incomes diminished ${ }^{1}$. Evidently, the reliability of politicians is the main determinant of how strongly people believe in legitimacy of government in their country and political order. The premium paid for one point increase of reliability of politicians is worth .89 controlling for other variables. One can see that standardized coefficient for it is .29 , much larger than the effect of any other variables included in the model. This is a telling illustration of the truth that promise-keeping, or generally, reputation of politicians, and the virtue of honoring contracts are decisive way in which they can unfold some bindingness and legitimization force.

Certainly, behind this general effect there are peculiar effects for individual countries. For example, in Polish case, as Edmund Mokrzycki (2002: 140) elaborated on it, immaturity of democracy may be gauged by that it ends next day after parliamentary election It is true that collapse of communism did not erase division between «us» and «theirs» and authorities are still regarded as an inimical and alien.

The second most important determinant of legitimacy is satisfaction with life. No matter how rich people are, no matter how exquisitely educated, performing which occupational roles, and so, there is the legitimacy premium for greater satisfaction with life. This result is consistent with earlier research (Inglehart 1999) and indicates that in strategies of gaining legitimacy the subjective feelings cannot be neglected.

It also holds for two other subjective factors - «satisfaction with incomes» should have positive effect on legitimacy in comparison with category of people who are modest or discontent with their incomes. This prediction is supported in that the coefficient for this dummy variable is .60 which indicates that category of those who admitted to «live comfortably on present income» give substantially higher support for political system than those who were dissatisfied with

1 Participation in voluntary organizations was excluded from model 3 after we checked that it did not affect legitimization in a statistically significant way. 
their material position or complained. There is also a fairly large, positive effect of feeling of security concerning one's position on the labor market. When selfassessed chances of getting a similar or better job increase by 1 point on the 10point scale, the legitimacy increases by .08 point other things equal.

Hypothesis advanced by Putnam, concerning effect of trust, proposes that higher interpersonal trust strengthens confidence with various agencies of state. Indeed effect of interpersonal trust proves true - belief that people can be trusted, try to be helpful and fair, is largely independent of other determinants of legitimacy and its standardized effect (.18) is larger than any other independent variable except of reliability of politicians and satisfaction with life. Broadly speaking, this result provides strong evidence for the thesis that legitimacy requires trust - which implies clear causal relationship in which trust is prior to legitimacy. However, this is by no means certain and in view of critical interpretations of the Putnam's theory one cannot exclude possibility that trust not only affects legitimacy but is also affected by it. According to Jean Cohen (1999), legal norms of procedural fairness, impartiality and justice, that limit favoritism and protect merit, are the sine qua non for society wide «general trust». In view of this argumentation, rights and norms ensure that trust is warranted and work as «functional equivalence» for personalized trust. Thus, there is reciprocal causation between trust and legitimacy and interpretations assuming unidirectional causation are simplified and biased.

In order to carry out rigorous test of reciprocal causation one need panel data with trust and legitimacy measured in two points of time. Since this kind of data is not available we will test this hypothesis without assuming timing. This model posits only reciprocal causation of legitimacy and trust that is people express confidence to authority because state fulfills obligations and such generated legitimacy is conducive to interpersonal trust. For 21 countries I estimated separately structural equations provided by the LISREL program where trust and legitimacy were latent variables. Our model joins measurement model which specifies the relationships of component (observed) items to latent variables, to a latent-variable model 0 the latter shows the effects of latent variables on one another (Bollen 1989). The aim was to show how strongly level of trust, indicated by three variables described above, affects legitimacy, indicated by three measures (also previously defined), and conversely - how strongly legitimacy affects trust. The standardized coefficients shown in first column of Table 3 are the maximum likelihood estimates of the model based on the sample correlation matrix. Since product-moment correlation is biased estimates of the true correlations of the latent dimensions we replaced product-moment correlations with polychoric and polyserial correlations estimated by maximum-likelihood (Joreskog and Sorbom 1989: 223238). In the last three columns of Table 3 we present conventional indices of goodness-of-fit of the model that is chi-square, AGFI (Adjusted Goodness of Fit Index) and RMSA (Root Mean Square Error for Approximation).

Table 3 shows that in each country both effects are substantial and statistically significant, however, in majority of countries trust more strongly affects le- 
Table 3

Structural equation model testing reciprocal effects of legitimacy and trust in 21 countries

\begin{tabular}{|l|c|c|c|c|r|}
\hline \multicolumn{1}{|c|}{ Country } & $\begin{array}{c}\text { Trust } \rightarrow \\
\text { Legitimacy }\end{array}$ & $\begin{array}{c}\text { Legitimacy } \\
\rightarrow \text { Trust }\end{array}$ & Chi-square/df & RMSA & AGFI \\
\hline Austria & .26 & .24 & 45.2 & .06 & .99 \\
Belgium & .59 & .39 & 44.1 & .06 & .99 \\
Czech Republic & .48 & .45 & 16.8 & .03 & 1.00 \\
Denmark & .34 & .28 & 57.8 & .04 & .99 \\
Finland & .56 & .37 & 6.0 & .03 & .99 \\
Germany & .34 & .39 & 44.6 & .06 & .99 \\
Greece & .32 & .36 & 79.0 & .08 & .98 \\
Hungary & .40 & .47 & 48.1 & .06 & .99 \\
Ireland & .35 & .25 & 37.1 & .05 & .99 \\
Israel & .39 & .31 & 57.6 & .07 & .99 \\
Italy & .25 & .26 & 92.1 & .09 & .99 \\
Luxembourg & .57 & .22 & 36.3 & .05 & .99 \\
Netherlands & .56 & .45 & 52.9 & .06 & .99 \\
Norway & .54 & .30 & 3.4 & .05 & .99 \\
Poland & .46 & .32 & 2.3 & .04 & .99 \\
Portugal & .38 & .40 & 122.5 & .10 & .97 \\
Slovenia & .57 & .40 & 57.1 & .07 & .99 \\
Spain & .28 & .34 & 57.0 & .06 & .99 \\
Sweden & .56 & .34 & 14.1 & .03 & 1.00 \\
Switzerland & .48 & .33 & 24.2 & .04 & .99 \\
United Kingdom & .45 & .38 & 33.6 & .06 & .99 \\
\hline
\end{tabular}

gitimacy than other way round. It is only in five countries, namely in Greece, Germany, Hungary, Italy, and Portugal, where effect of legitimacy is stronger. Predominance of stronger effect of interpersonal trust suggests that, generally, it is prior to legitimacy and serves as a precondition of support for government and state. At the same time, one should not overlook not negligible reverse effect. While it is generally true that without interpersonal trust prospects for legitimacy are bleak, it is also true that there is a mutual causation between legitimacy and beliefs that people can be trusted.

Increasing calls for welfare provisions are taken as the focal point in the legitimacy crisis theories. Another threat to legitimacy arises from leftists orientations whereas greater symphaties to the right increase political support. Both predictions are in accord with our findings. One can see first, that every onepoint increase on the left-right scale is related to significant increment of .18 point on the legitimacy scale. Second, legitimacy premium is .21 for one point increase on the composite scale of the orientations disregarding welfare state. In- 
terestingly, the latter finding suggests that favourable conditions created for legitimacy by welfare regimes do not contradict that claims to the welfare state may undermine support for political system on individual level as hypotheses on the crisis of legitimacy imply. It may well be that negative evaluations of the welfare state measures enhance legitimizations even in Scandinavian societies. By the way, according to ranking of 21 countries on our «anti-welfare» scale, citizens of Scandinavian societies look relatively critical to the welfare state as picked up by attitudes to interventionism of government, policy of reduction of differences in incomes, and the need for strong trade unions. Sweden, Norway, and Finland locate near the top with scores ranging from 7.19 to 7.78 . The highest anti-welfare attitudes took place in Denmark (8.55) followed by Netherlands (8.20) and Great Britain (7.99).

\section{DETERMINANTS OF MACRO-LEVEL: STANDARD OF LIFE, MIDDLE CLASS, AND CORRUPTION}

Moving from analysis of the individual to global-level variables one can determine to what extent legitimacy depends on the general well-being or inadequate performance of agencies of state as indicated by a corruption index. In seeking for legitimacy it should matter whether economy performs well and is marked with low unemployment rate or, conversely, whether one lives in the poor country with corrupted administration that does not comply with the rules. Earlier analyses on sources of legitimacy hinted at important role played by economic development, corruption, level of unemployment and strong middle class but they neither specify their net effects nor compare them with individual variables (Inglehart, 1999).

To determine these questions we turn from simple cross-sectional research design to the analysis of data defined at different level of observations, namely countries and individuals within these countries. The design of such studies reflects several specific methodological problems summarised in a term of ,multilevel problems» (see Bryk and Raudenbush 1992; Hox 1994). Because respondents are hierarchically nested within the units of the GNP, unemployment rates, etc., a hierarchical model must be used for the analysis of individuals and effects of the four contextual variables. I employed the hierarchical linear regression model also known as the random coefficient model that has been described in several articles and books (e.g. Bryk and Raudenbush 1992). The hierarchical linear model HLM 5 procedure (see Raudenbusch et al. 2000) can deal with these problems and is adopted in the estimation model in this study.

Since collinearity between our contextual variables is high - that could bias estimates of their effects- I examined them within four separate models. The parameter estimates for these models are summarised in Table 4. Columns $1,2,3$, and 4 show the effects of schooling, social class, log incomes, etc., and, respectively, effects of GNP per capita, corruption, level of unemployment and size of the middle class. 
Table 4

Parameter estimates for individual and macro-systemic determinants of legitimacy for pooled cross-country data in $\mathbf{2 0 0 2}$

\begin{tabular}{|c|c|c|c|c|}
\hline Independent variables & $I$ & II & III & IV \\
\hline Years of schooling & -.03 & -.03 & -.03 & -.03 \\
\hline Occupational category: & & & & \\
\hline $\begin{array}{l}\text { Professionals and } \\
\text { managers }\end{array}$ & .14 & .12 & .12 & .20 \\
\hline Lower professionals and & & & & \\
\hline managers & -.13 & -.13 & -.13 & -.14 \\
\hline Owners & -.19 & -.18 & -.18 & -.16 \\
\hline Skilled workers & .03 & .03 & .03 & .01 \\
\hline Unskilled workers & -.01 & .00 & .00 & -.03 \\
\hline Farmers and agricultural & & & & \\
\hline labourers & .28 & .27 & .27 & .26 \\
\hline Log of family incomes & $-.11 *$ & $-.10^{*}$ & $-.10^{*}$ & $-.05^{*}$ \\
\hline Reliability of politicians & $1.00^{* *}$ & $.71 * *$ & $.71 * *$ & $.72 * *$ \\
\hline Trust & $.14^{* *}$ & $.14^{* *}$ & $.14 * *$ & $.15^{* *}$ \\
\hline Satisfaction with life & $.57 * *$ & $.57 * *$ & $.58 * *$ & $.58 * *$ \\
\hline Left-right & $.18^{* *}$ & $.14^{* *}$ & $.14 * *$ & .14 \\
\hline Anti-welfare & $.18^{* *}$ & $.18^{* *}$ & $.18 * *$ & .19 \\
\hline Satisfaction with incomes & $.67 * *$ & $.67 * *$ & $.67 * *$ & $.67 * *$ \\
\hline Finding job & $-.02 * *$ & $-.02 * *$ & $-.02 * *$ & $-.02 * *$ \\
\hline Interest in politics & -.03 & -.03 & -.03 & \\
\hline GNP & $.11^{*}$ & - & - & - \\
\hline GNP $*$ reliability of & & & & \\
\hline politicians & $-.01 *$ & - & - & - \\
\hline GNP * left-right & $.03^{*}$ & - & - & - \\
\hline Corruption & - & $.38^{*}$ & - & - \\
\hline Unemployment $(\%)$ & - & - & $-.09 *$ & - \\
\hline Size of the middle class & - & - & - & .07 \\
\hline Intercept & 1.7 & 1.41 & 4.74 & 2.58 \\
\hline Deviance & 26,200 & 26,061 & 26,041 & 26,340 \\
\hline Log-likelihood/df & $13,100 / 154$ & $13,031 / 154$ & $13,021 / 154$ & $13,078 / 154$ \\
\hline Constant & 1.67 & 1.41 & 4.74 & 2.58 \\
\hline
\end{tabular}

$* p<.05 . \quad * * p<.01$.

Let us look, first, on the role of level of economic development. The positive and significant effect of the GNP per capita indicates that governments in wealthy nations can win higher support. When GNP increases by one thousand Euro per capita, legitimacy increases by .11 point other things equal. It suggests that although much depends on reliability of politicians it seems generally better to rule in wealthy than in poor nations. I addition I introduced interaction effects between 
GDP and reliability of politicians and - separately - GDP and left-right scale to test whether higher economic development is so pervasive. The coefficients suggest that both evaluation of politicians and rightist symphaties are positively related to GDP. If we were to take the point-estimate at face value, we would conclude that increase of GDP by 1000 euro increases effects of reliability of politicians on legitimacy by 0,01 point, and interaction effect for right-left is $0,3^{2}$.

Our findings demonstrate that it is also easier to rule in the countries with relatively low unemployment which can be taken as another indicator of economic prosperity and competence of government in dealing with recessions. There is a clear decrease (by .09 points) of legitimacy with every one percent of unemployment increase which shows that the latter weakens credibility of the political system and ruling class.

High corruption betrays failure of the system and law to constrain and guide action of the officeholders. The widely publicized highly visible experience of corruption were attributed to legitimacy crisis in recent time by Offe (1999) and other writers. In ranking of Corruption Perception Index, the lowest incidence of corruption - across analysed 21 nations - have been in Finland (9.9), followed by Denmark (9.5) and Sweden (9.0). It was the highest in Czech Republic (3.5) and in two other post-communist countries, namely in Poland (4.1) and Hungary (4.2). As our analysis displays, legitimacy is negatively associated with corruption in that increase of the latter by 1 point results in .38 point decrease of legitimacy.

Finally, there was no statistically discernible effect of having big middle class in generating massive support for government. As statistically not significant coefficient for this variable shows, societies characterised by a relatively numerical middle class do not seem to be more likely to induce higher legitimacy than societies characterised by small middle class. Though unambiguous, this finding does not undermine theories of legitimacy saying that stable democracy requires a large middle class because it tends to maintain economic stability and dismisses extremism on either side. What we established is that in seeking for sources of legitimacy in the size of the middle class in itself one can hardly find any payoffs. That's what we get to know.

\section{CONCLUSION}

Many authors, bearing mostly on theoretical reflection, have associated legitimacy with both individual and global-level characteristics. My focus has been to assess underpinnings of legitimacy in a quantitative way. To accomplish it I use data of the European Social Survey 2002 with legitimacy defined in terms of support for government, democracy, and economic policy of state.

${ }^{2}$ I introduced selectively to this equation various combination of interaction effects - those involving contextual variables- and keep only the two significant ones. 
Findings presented below may be regarded as relatively newest characteristics of ,deficit» of legitimization. Political systems that mostly required legitimization included, first of all, Poland, where legitimacy appeared the lowest. Poland was followed by Israel and Germany. On the opposite pole of the legitimacy scale located Denmark, Finland, and Sweden. We found our results consistent with theoretical predictions in that the most important determinant of legitimacy has been reliability of politicians. Thus, the basic answer to the question on how government can legitimate itself is this: politicians have to comply with rules. Not much less depends on general satisfaction with life and interpersonal trust. We found also substantial support for hypotheses saying that legitimacy is positively correlated with rightist orientations in politics and rejection of interventionist role of the state. As far as effects of socio-economic status is concerned, the results show that governments can count mostly on individuals with higher schooling, belonging to professionals and managers and better off in terms of incomes, and generally - socio-economic position.

These results were obtained in the pooled samples for 21 countries since our primary goal was to illuminate general tendencies. Broadly speaking they represent European societies in overall. An important, although quite different question to determine, remains in which countries these general relationships were reflected most and in which least. As analyses carried out separately for 21 analyzed countries (not shown here) disclosed there was nothing like a «core» countries that fit general tendencies best. At the same time, one can hardly find «outliers». Evidently, «reliability of politicians» played the greatest part across all 21 countries although its net effect differed: it have been relatively the most important determinant of legitimacy in Greece, Denmark, and Germany (with metric coefficients ranging between 1.21-1.10), while it was at its lowest in Netherlands (.57) and Sweden (.72). One can easily see that this configuration looks patchy and circumstantial which does not allow interpreting theirs in terms of some coherent theory. As regards effect of general satisfaction with life it once again appeared most strongly in Greece (.71) although in other countries it affected legitimacy not much less. To recapitulate, on the one hand, any consistent cross-national patterns emerged, there were no striking political, economic, or cultural cleavages but -on the other hand - there were also any outstanding effects for individual societies.

Analysis of the global determinants of legitimacy revealed what -bearing on theoretical predictions- could be expected. Effects of GNP per capita, unemployment rate and corruption level turned out substantial which suggests that it is more difficult to win legitimacy in countries that are poor, suffer from corruption, and economic recession, independent of reliability of politicians, satisfaction with life, interpersonal trust and other individual variables. It is notably difficult to pursue various channels through these macrostructural factors are translated to individual minds' in the process of generating legitimacy. What seems unequivocal is that all these factors cannot be overlooked since they put serious constraints on strategies seeking for political support. 
Let us make a general comment. Every turn to democratization has its own pathology in that of elite democracy in Schumpeterian forms. The inescapable issue has to do with the search for an appropriate form for the balance between the state and civil society. In post-communist countries democracy has to combine the transmutation of the party-state into liberal state and the transmutation of people in the civil society. On the first sight the problem how to secure respect for the state refers to all post-communist societies. However, not unexpectedly, it shows particularly acute in Poland where there has been scant experience of legitimate political authority for the last two centuries. In Western Europe the approximation of a society of citizens who are «civil» to one another has taken generations to form. In Southern European countries - such as Greece, Portugal, and Spain - it took even longer which our analyses seem to confirm. The postcommunist societies have to move forward more quickly if legitimacy is to be secured. 


\section{REFERENCES}

BELL, D. (1976): Cultural Contradictions of Capitalism. London, Heinneman.

Bellah, R. N.; Madsen, R.; Sullivan, W. M.; Swindler, A. and Tipton, S. M. (1985): Habits of the Heart: Individualism and Commitment in American Life. New York, Harper \& Row.

BOLLEN, K. (1989): Structural Equations with Latent Variables. New York, John Wiley \& Sons.

Bryk, A. S. and Raudenbush, S. W. (1992): Hierarchical Linear Models. Applications and Data Analysis Methods. London, Sage Publications.

BURKHART, R. E. and LEwIS-BECK, M. (1994): «Comparative democracy. The economic development thesis". American Political Science Review, 88, pp. 903-910.

COHEN, J. (1999): «Trust, well-being and democracy», in M. Warren (ed.), Democracy and Trust. Cambridge, Cambridge University Press, pp. 88-120.

Coleman, J. S. (1990): Foundations of Social Theory. Cambridge, Mass.: Harvard University Press.

Curran, J. and Blackburn, R. (1991): Paths of Enterprise. The Future of Small Business. London, Routledge.

DiAmOND, L. (1992): «Economic development and democracy revisited». American Behavioral Scientist, 35, pp. 450-499.

DiAmond, L.; LinZ, J. J. and LiPSET, S. M. (eds.) (1989): Democracy in Developing Countries. Boulder, Colo: Lynne Rienner Publishers.

DEUTSCH, K. (1961): «Social mobilization and political development». American Political Sciences Review, 55, pp. 493-514.

EAston. D. (1953): The Political System. An Inquiry into the State of Political Science. New York, Kopf.

Elster, J.; OfFe, C. and Preuss, U. K. (1998): Institutional Design in Post-Communist Societies: Rebuilding the Ship at Sea. Cambridge, Cambridge University Press.

ERIKson, R. and GoldThorpe, J. H. (1992): The Constant Flux: A Study of Class Mobility in Industrial Societies. Oxford, Clarendon Press.

ETZIONI, A. (1995): Rights and the Common Good: The Communitarian Perspective. New York, St. Martin's Press.

JoRESKOG, K. G. and SORBOM, D. (1989): LISREL 7. User's reference Guide. Lincolnwood, Ill.: Scientific Software, Inc.

HABERMAS, J. (1987): The Theory of Communicative Action, vol. II. Boston, Beacon Press.

Harrington, M. (1983): The Politics at God's Funeral: The Spiritual Crisis of Western Civilization. New York: Holt, Rinehart and Winston.

HoX, JoOP J. and KREFT, Ita G. (1994): «Multilevel analysis methods». Sociological Methods and Research, 22, pp. 283-299.

HymaN, H. (1954): «The value systems of different classes», in: R. Bendix and S. M. Lipset (eds.), Class, Status and Power. Glencoe, 11l.: Free Press.

INGLEhart, R. (1990): Culture Shift in the Advanced Societies. Princeton, Princeton University Press.

- (1999): «Trust, voluntary association and workable democracy: the contemporary American discourse of civil society», in: M. Warren (ed.). Democracy and Trust. Cambridge, Cambridge University Press, pp. 208-148.

Kelley, J. and EVANS, M. (1993): «The legitimation of inequality: occupational earnings in nine nations». American Journal of Sociology, 99. 
KLINGEMAN, H-D. (1979): «Measuring ideological conceptualizations», in S. H. Barnes and M. Kaase (eds.), Political Citizens and the Action. Beverly Hills, Calif.: Sage, pp. 215-254.

Kornhauser, A. (1959): The Politics of Mass Society. Glencoe, Ill: Free Press.

LANE, J.-E. and ERSSON, S. (2003): Democracy. A Comparative Approach. London and New York, Routledge.

LASCH, Christopher (1982): The Culture of Narcissism. New York, Norton.

LERNER, D. (1958): The Passing from Traditional Society. Modernizing of the Middle East. New York, Free Press.

Linz, J. and Valanzuela, A. (1994): The Failure of Presidential Democracy. Baltimore MD: the Hopkins University Press.

LiPSET, S. M. (1983): Political Man. The Social Bases of Politics. Baltimore, MD: Johns Hopkins University.

Medrano D. (1996): «Does Western Europe stop at the Pyrenees?» in: L. Halman and Nevitte (eds.), Political Values Change in Western Democracies. Integration, Values, Identification and Participation. Tilburg, Tilburg University Press.

MOKRZYCKI, E. (2002): «Demokracja negocjacyjna [Negotiating Democracy]», in: E. Mokrzycki, A. Rychard, A. Zybertowicz (eds.), Utracona dynamika? O niedojrza_o_ci polskiej demokracji [Lost Dynamics? On Immature Polish Democracy]. Warszawa, Wydawnictwo IFiS PAN, pp. 129-146.

O'Connor, J. (1973): The Fiscal Crisis of the State. New York, St. Martin's Press.

OfFE, C. (1996): Modernity and State: East, West. Cambridge, Mass. MIT Press.

- (1999): «How can we trust our fellow citizens?», in: M. Warren (ed.), Democracy and Trust. Cambridge, Cambridge University Press, pp. 42-87.

Putnam, R. (1993): Making Democracy Work: Civic Traditions in Modern Italy. Princeton, Princeton University Press.

RAUDENBUSH, S. W., et al. (2000): HLMS. SSJ Scientific Software. Lincolnwood II.

Runciman, W. (1966): Relative Deprivation and Social Justice. London, Routledge and Kegan Paul.

SCHumPeter, J. A. (1952): Capitalism, Socialism, and Democracy. London, George Allen and Unwin.

SzTOMPKA, P. (1996): «Trust and emerging democracy». International Sociology, 11, pp 37-62.

WARren, M. E. (1999): Democracy and Trust. Cambridge, Cambridge University Press. 


\begin{abstract}
Analyses on sources of legitimization bear, mostly, on theoretical reflection. My focus here is to assess underpinnings of legitimacy in a quantitative way. This is an empirical study which examines determinants of subjective legitimization of government and social system in 21 European societies. Data come from first edition of European Social Survey carried out on national random samples in 2002. Legitimization is defined in terms of support for government, democracy, and economic policy of state given by respondents in answering research questions. My analyses aim, first, to assess relative»level» of legitimization throughout analyzed societies. Second, various sets of individual measures of social characteristics and attitudes are employed in order to establish some universal rules of requirements of legitimacy. Third, an attempt is made to disclose macro-structural determinants of the inter-country variation in legitimacy related to economic development, political system, degree of corruption and social structure measures. Finally, these findings are discussed in reference to most recent hypotheses concerning effect on legitimization of the welfare state and decreasing confidence and trust.
\end{abstract}

\title{
ABSTRACT
}

Legitimization, degitimacy, social system.

\section{RESUMEN}

El análisis sobre las fuentes de la legitimación se basa fundamentalmente en la reflexión teórica. Mi enfoque aquí es evaluar las bases de la legitimación cuantitativamente. Este es un estudio empírico que examina los determinantes de la legitimación subjetiva del gobierno y el sistema social en 21 sociedades europeas. Los datos parten de la primera edición de la Encuesta Social Europea llevada acabo sobre muestras aleatorias en 2002. La legitimación es definida en términos de apoyo al gobierno, la democracia y la política económica del estado dado por los encuestados. Mi análisis trata, primero, de valorar el nivel relativo de legitimación a través de las sociedades analizadas. Segundo, se utiliza un conjunto de indicadores de características sociales y actitudes para establecer algunas reglas universales sobre las condiciones necesarias de la legitimación. Tercero, se intenta revelar los determinantes macroestructurales de las variaciones de legitimación entre países que tienen relación con el desarrollo económico, el sistema político, el grado de corrupción y algunas medidas de estructura social. Finalmente, estos hallazgos se debaten a la luz de las más recientes hipótesis sobre el efecto del estado de bienestar sobre la legitimación y el descenso de la confianza.

\section{ABSTRACT}

Legitimización, degitimidad, sistema social. 